\title{
Association Between Heart Rate-corrected QT Interval and Severe Peripheral Arterial Disease in Patients with Type 2 Diabetes and Foot Ulcers:Aa Case Control Study
}

\section{Jing Hong}

The First Affiliated Hospital of Wenzhou Medical University

Wen-Yue Liu

The First Affiliated Hospital of Wenzhou Medical University

Xiang Hu

the first affiliated hospital of wenzhou medical university

\section{Fei-Fei Jiang}

The First Affiliated Hospital of Wenzhou Medical University

\section{Ze-Ru Xu}

the first affiliated hospital of wenzhou medical university

\section{Fang Li}

Ruian Traditional Chinese Medicine Hospital

\section{Fei-Xia Shen}

the first affiliated hospital of wenzhou medical university

Hong Zhu ( $\nabla$ zhuhong@wmu.edu.cn)

The First Affiliated Hospital of Wenzhou Medical University https://orcid.org/0000-0002-9024-0221

\section{Research}

Keywords: Diabetes, Foot ulcer , QTc interval, peripheral arterial disease

Posted Date: October 26th, 2020

DOI: https://doi.org/10.21203/rs.3.rs-95090/v1

License: (c) (1) This work is licensed under a Creative Commons Attribution 4.0 International License. Read Full License 


\section{Abstract}

Background: Half of patients with diabetes and foot ulcers (DFUs) have co-existing peripheral arterial disease (PAD). Prolonged heart rate-corrected QT (QTC) interval was found to be associated with PAD in a general population. The goal of the present study was to investigate the relationship between QTc interval and PAD in patients with DFUs.

Methods: The present multi-center cross-sectional study enrolled 281 patients with DFUs. Severity of PAD was classified as no-severe PAD group (no obvious abnormality or plaques) and severe PAD group (stenosis or occlusion) according to duplex ultrasonography. QTc was calculated according to the Bazett formula. The study population was divided into subgroups based on the QTc tertiles.

Results: The patients with severe PAD had longer QTc interval $(P=0.004)$ and higher prevalence of prolonged QTc $(P=0.042)$ than those with no-severe PAD. After adjustment for gender and age, partial correlation analysis revealed positive relationship of QTc with prevalence of severe DFUs $(r=0.194, P=$ $0.001)$ and severe PAD $(r=0.118, P=0.048)$. Univariate logistic analysis showed that the QTc was positively associated with severe PAD (odds ratio $[\mathrm{OR}]=1.010, P=0.014$ ). Compared to those in lowest tertile of QTC, the ORs for severe PAD were increased significantly and independently for those in upper tertiles of QTc (both $P<0.05)$.

Conclusions: Prolonged QTc interval was independently associated with severe PAD in patients with DFUs, which might indicate the worse progression of peripheral atherosclerosis in early stage for this population.

\section{Introduction}

Diabetic foot disease, a common complication in patients with diabetes ${ }^{[1]}$, is generally associated with high prevalence of severe macroangiopathic comorbidities that result in high morbidity and mortality [2]. A total of $50 \%$ of patients with diabetes and foot ulcers (DFUs) have co-existing peripheral arterial disease (PAD) ${ }^{[3]}$. Patients with DFUs and lower extremity PAD have the greatest risk of limb loss. PAD is usually asymptomatic in patients with diabetes. For these patients, co-existing sensory neuropathy may mask symptoms of intermittent claudication and ischemic rest pain ${ }^{[4]}$. The diagnosis of PAD is mostly made once a DFU is present, pointing out the need for earlier screening and the assessment of arterial insufficiency ${ }^{[5]}$.

The QT interval, defined as the time between the beginning of the Q wave and the end of the T-wave represents the duration of the electrical depolarization and repolarization of the ventricular walls ${ }^{[6]}$. Heartrate-corrected QT (QTC) interval prolongation is a possible consequence of cardiac autonomic neuropathy and is a predictor of lethal arrhythmias ${ }^{[7,8]}$. It has been demonstrated that patients with diabetes have a more frequent occurrence of QTc prolongation than patients without diabetes ${ }^{[9]}$. QTc interval also 
increases during hypoglycemia ${ }^{[10,11]}$. Studies indicated that QTc interval was associated with the risk of cardiovascular diseases (CVDs), all-cause mortality, sudden cardiac mortality and stroke ${ }^{[12-18]}$.

Few studies have addressed the association of QTc interval with clinical arterial disease ${ }^{[18-21]}$. Clinical studies found associations between carotid intima media thickness and QTC prolongation not only in patients with type 2 diabetes but also in a clinically healthy population ${ }^{[19,21]}$. Links between pulse wave velocity and QTc have been found in a clinically healthy population ${ }^{[20]}$. Prolonged QTc was found to be associated with PAD in a general population ${ }^{[18]}$, but no study to date has identified a link between the severity of PAD and QTc in DFUs patients. Therefore, we performed a cross-sectional study to assess the association of QTc interval with the risk of severe PAD in DFUs patients measured by duplex ultrasonography.

\section{Materials And Methods Study population}

We used data from multi-center cross-sectional survey based on 6 medical institutions in Wenzhou city, China (The first affiliated hospital of Wenzhou medical university, Wenzhou people's hospital, Rui'an people's hospital, Rui'an Traditional Chinese Medicine Hospital, Yueqing people's hospital, Pingyang people's hospital). A total of 472 patients diagnosed with DFUs according to the 2015 International Working Group on the Diabetic Foot (IWGDF) diagnostic criteria ${ }^{[22]}$ were enrolled from October 2015 to September 2019. The exclusion criteria included previous myocardial infarction, congenital long QT syndrome, pacemaker rhythms, atrial fibrillation, other arrhythmias, hypokalemia and under medication affecting QTc interval (antiarrhythmic, beta-blocker, digitalis, quinolone antibiotics and psychotropic drugs) [23]

Finally, 281 DFUs patients were included in the present study. Degree of severity of DFUs was subdivided according to Wagner classification ${ }^{[24]}$ (grade score $0 \sim 5$ ) and categorized as no-severe DFUs group (Wagner grade score<3) and severe DFUs group (Wagner grade score $\geq 3$ ).

The study protocol was approved by the ethics committee of the First Affiliated Hospital of Wenzhou Medical University. Written informed consent was obtained from all patients prior to their participation.

\section{Data collection and measurements}

All patients were assessed by diabetologists and diabetic care nurses in six hospitals of a diabetic foot federation. Patient history included data on demographic characteristics, diabetes duration, coronary heart disease, hypertension and lifestyle habits, including smoking and drinking. Resting blood pressure was recorded. Hypertension was defined as the use of hypertensive medications or a mean resting systolic blood pressure (SBP) $\geq 140 \mathrm{mmHg}$ or diastolic blood pressure (DBP) $\geq 90 \mathrm{mmHg}$. Mean arterial pressure $(\mathrm{MAP})$ was calculated as follows: $\mathrm{MAP}=(\mathrm{SBP}+2 * \mathrm{DBP}) / 3$. Blood samples were collected and analyzed from antecubital vein. Among them, laboratory parameters including high-density lipoprotein- 
cholesterol (HDL-C), low-density lipoprotein-cholesterol (LDL-C), total cholesterol (TC), triglyceride (TG), hemoglobin A1c (HbA1c), albumin (ALB) Hemoglobin $(\mathrm{Hb})$ and creatinine were subsequently analyzed by an automated analyzer (Abbott AxSYM, Park, IL). Estimated glomerular filtration rate (eGFR) was calculated by using the EPI equation [25].

\section{Definition and grouping of PAD}

The bilateral lower extremity arteries (femoral artery, superficial femoral artery, popliteal artery, anterior tibial artery, posterior tibial artery and dorsalis pedis arteries) of patients were examined by duplex ultrasonography for intima-media thickness, plaque occurrence, stenosis, blood vessel diameter and filling defect in blood flow. PAD was defined by qualified, experienced ultrasonic diagnostic experts. Degree of severity of PAD was subdivided according to duplex ultrasonography and classified as nosevere PAD group (no obvious abnormality or plaques) and severe PAD group (stenosis or occlusion).

\section{QTc measurement}

All patients had a standard 12-lead resting ECG recorded within 24 hours of admission. The ECGs were reviewed for rhythm analysis and measurements by two independent cardiologists. The QT interval was calculated from the beginning of the QRS complex to the end of the T wave. The value was then corrected for heart rate according to the Bazett formula: QTc = QT interval/square root of the R-R interval $(\mathrm{QTc}=\mathrm{QT} /[\mathrm{RR}] 1 / 2)$. QTc $\geq 440 \mathrm{~ms}$ was defined as Prolonged QTc. In order to prevent the QTc from being overvalued or undervalued, only patients with a normal pulse rate (60 to 100 beats $/ \mathrm{min}$ ) were enrolled in the present study.

\section{Statistical analysis}

The one-sample Kolmogorov-Smirnov test was used in order to examine the normality of distributions. Data were presented as $\mathrm{n}(\%)$, mean \pm standard deviation, or, in the case of skewed variables, as median and interquartile range (IQR). Continuous variables were compared using two-sided student's $t$ test, oneway ANOVA (for normally distributed variables) or Mann-Whitney U test, Kruskal-Wallis test (for skewed variables). Categorical variables were compared using Chi-squared test. Spearman and partial correlation analyses were conducted to assess the relationship between clinical characteristics and QTc. In order to assess the correlation of QTc and severe PAD, the study population was divided into tertiles according to QTc. Univariate logistic regression analyses were performed to determine the risk factors for severe PAD. Multivariable logistic regression analysis was performed to determine whether the association persists after adjusting confounding variables. Models were adjusted for age, sex, duration of type 2 diabetes, smoking status, alcohol consumption, systolic blood pressure, ALB, creatinine, $\mathrm{Hb}, \mathrm{LDL}$ and $\mathrm{HbA} 1 \mathrm{c}$. The adjusted odd ratio (OR) and $95 \%$ confidence interval $(\mathrm{Cl})$ were calculated. $\mathrm{P}$ values of 0.05 were considered statistically significant for all tests. Statistical analyses were performed using SPSS (IBM, IL, USA) version 22.

\section{Results}




\section{Clinical characteristics of Study population}

According to the duplex ultrasonography, among 281 DFUs patients, 122 (43.4\%) cases of severe PAD were identified. Compared to no-severe PAD group, the severe PAD group were older, and had longer diabetic foot duration, higher prevalence of hypertension, and lower eGFR (all $P<0.05$, Table 1 ). 
Table 1

Baseline characteristics of DFUs patients with and without severe PAD

\begin{tabular}{|c|c|c|c|}
\hline Characteristic & $\begin{array}{l}\text { No-severe PAD } \\
(\mathrm{N}=159)\end{array}$ & $\begin{array}{l}\text { Severe PAD } \\
(N=122)\end{array}$ & $P$ value \\
\hline Male (\%) & $106(66.7 \%)$ & $71(58.2 \%)$ & 0.145 \\
\hline Age (years) & $66(56-74)$ & $72(66-80)$ & $<0.001$ \\
\hline Smoking (\%) & $56(35.4 \%)$ & $38(31.1 \%)$ & 0.450 \\
\hline Alcohol use (\%) & $49(30.8 \%)$ & $31(25.4 \%)$ & 0.319 \\
\hline Diabetes duration (years) & $10(6-17)$ & $10(8-20)$ & 0.360 \\
\hline Diabetic foot duration (day) & $20(7-30)$ & $30(10-60)$ & 0.026 \\
\hline Severe DFUs (\%) & $66(41.5 \%)$ & $58(47.5 \%)$ & 0.313 \\
\hline Hypertension (\%) & $84(52.8 \%)$ & $96(78.7 \%)$ & $<0.001$ \\
\hline $\mathrm{SBP}(\mathrm{mmHg})$ & $141 \pm 22$ & $146 \pm 21$ & 0.105 \\
\hline $\mathrm{DBP}(\mathrm{mmHg})$ & $75 \pm 12$ & $76 \pm 11$ & 0.746 \\
\hline MAP $(\mathrm{mmHg})$ & $97 \pm 13$ & $99 \pm 13$ & 0.268 \\
\hline Creatinine $(\mu \mathrm{mol} / \mathrm{l})$ & $69(58-91)$ & $77(59-107)$ & 0.058 \\
\hline eGFR (EPI)『mL/min/1.73m2凹 & $88.9(67.4-100.3)$ & $78.4(50.3-94.5)$ & 0.009 \\
\hline $\operatorname{ALB}(\mathrm{g} / \mathrm{L})$ & $34.4(30.1-37.7)$ & $34.9(31.1-37.9)$ & 0.667 \\
\hline $\mathrm{Hb}(\mathrm{g} / \mathrm{L})$ & $119.5(104.8-133.3 \rrbracket$ & $118.0(105.5-128.0)$ & 0.420 \\
\hline $\mathrm{HbA1c}(\%)$ & $9.5(7.7-11.3)$ & $9.0(7.3-11.4)$ & 0.400 \\
\hline $\mathrm{TC}(\mathrm{mmol} / \mathrm{L})$ & $4.2(3.3-4.9)$ & $4.11(3.30-5.16)$ & 0.932 \\
\hline $\mathrm{TG}(\mathrm{mmol} / \mathrm{L})$ & $1.22(0.88-1.78)$ & $1.33(0.91-1.88)$ & 0.465 \\
\hline $\mathrm{HDL}-\mathrm{C}(\mathrm{mmol} / \mathrm{L})$ & $0.95(0.75-1.19)$ & $0.93(0.75-1.10)$ & 0.229 \\
\hline LDL-C (mmol/L) & $2.29(1.76-2.95)$ & $2.37(1.67-3.05)$ & 0.960 \\
\hline
\end{tabular}


Compared to No-severe PAD group, the severe PAD group had longer QTc interval (438 [423-455] versus 429 [407-445], $P=0.004)$ and higher prevalence of prolonged QTc (34.0\% versus $45.9 \%, P=0.042)$ (Fig. 1).

\section{Relationships between clinical characteristics and QTC}

Spearman correlation analysis showed that age, the prevalence of severe DFUs, ischemic ulcer and severe PAD were positively correlated with QTc, whereas male, eGFR, ALB, Hb, HDL-C, LDL-C, and prevalence of smoking were inversely associated with QTc (all $P<0.05$ ). After adjustment for gender and age, partial correlation analysis confirmed the positive relationship between the prevalence of severe DFUs $(r=0.194, P=0.001)$, severe PAD $(r=0.118, P=0.048)$ and QTc. Negative relationship between ALB $(r=-0.224, P<0.001), \mathrm{Hb}(r=-0.255, P<0.001), \mathrm{HDL}-\mathrm{C}(r=-0.162, \mathrm{P}=0.007)$, prevalence of smoking $(r=$ $-0.120, P=0.046$ ) and QTc were confirmed by partial correlation analysis. (Table 2 ). 
Table 2

Spearman rank correlation between clinical characteristics and QTC

\begin{tabular}{|c|c|c|c|c|}
\hline \multirow[b]{2}{*}{ Characteristic } & \multicolumn{2}{|l|}{ QTc } & \multicolumn{2}{|c|}{ QTc (gender,age adjusted】 } \\
\hline & $r$ & P-value & $\mathbf{r}$ & P-value \\
\hline Male (\%) & -0.140 & 0.019 & - & - \\
\hline Age (years) & 0.175 & 0.003 & - & - \\
\hline Smoking (\%) & -0.192 & 0.001 & -0.120 & 0.046 \\
\hline Alcohol use (\%) & -0.115 & 0.054 & -0.030 & 0.616 \\
\hline Diabetes duration (years) & 0.048 & 0.423 & -0.006 & 0.926 \\
\hline Diabetic foot duration $\rrbracket$ day $\rrbracket$ & 0.019 & 0.765 & -0.041 & 0.516 \\
\hline severe DFUs (\%) & 0.191 & 0.001 & 0.194 & 0.001 \\
\hline Ischemic ulcer (\%) & 0.132 & 0.027 & 0.078 & 0.194 \\
\hline Hypertension (\%) & 0.105 & 0.078 & 0.016 & 0.789 \\
\hline $\mathrm{SBP}(\mathrm{mmHg})$ & 0.004 & 0.947 & -0.008 & 0.900 \\
\hline $\mathrm{DBP}(\mathrm{mmHg})$ & -0.017 & 0.773 & 0.013 & 0.824 \\
\hline MAP $(\mathrm{mmHg})$ & -0.021 & 0.730 & 0.003 & 0.995 \\
\hline Creatinine $(\mu \mathrm{mol} / \mathrm{l})$ & 0.050 & 0.403 & 0.117 & 0.052 \\
\hline eGFR (EPI) (mL/min/1.73m2) & -0.162 & 0.007 & -0.077 & 0.199 \\
\hline $\mathrm{HbA1c}(\%)$ & 0.001 & 0.993 & -0.014 & 0.829 \\
\hline $\operatorname{ALB}(g / L)$ & -0.201 & 0.001 & -0.224 & $<0.001$ \\
\hline $\mathrm{Hb}(\mathrm{g} / \mathrm{L})$ & -0.294 & $<0.001$ & -0.255 & $<0.001$ \\
\hline $\mathrm{TC}(\mathrm{mmol} / \mathrm{L})$ & -0.088 & 0.147 & -0.109 & 0.072 \\
\hline TG (mmol/L) & 0.036 & 0.547 & -0.026 & 0.675 \\
\hline $\mathrm{HDL}-\mathrm{C}(\mathrm{mmol} / \mathrm{L})$ & -0.192 & 0.001 & -0.162 & 0.007 \\
\hline LDL-C (mmol/L) & -0.140 & 0.020 & -0.116 & 0.055 \\
\hline severe PAD (\%) & 0.174 & 0.004 & 0.118 & 0.048 \\
\hline $\begin{array}{l}\text { PAD: peripheral arterial disease } \\
\text { mean arterial pressure; eGFR: } \\
\text { HbA1c: hemoglobin A1c; TC: tc } \\
\text { density lipoprotein; QTc: heart- }\end{array}$ & $\begin{array}{l}\text { stolic blo } \\
\text { glomeru } \\
\text { sterol; TC } \\
\text { cted QT i }\end{array}$ & $\begin{array}{l}\text { pressure } \\
\text { iltration } \\
\text { glyceride } \\
\text { val. }\end{array}$ & $\begin{array}{l}\text { diastoli } \\
\text { LB: alb } \\
\text { : high-d }\end{array}$ & $\begin{array}{l}\text { essure; MAP: } \\
\text { hemoglobin; } \\
\text { protein; LDL: low }\end{array}$ \\
\hline
\end{tabular}




\section{Univariate and Multivariable logistic regression analyses for the risk factors of severe PAD}

Univariate logistic regression analyses were performed to determine the risk factors for severe PAD. Age, hypertension, QTc, serum creatinine and eGFR were found to be related to severe PAD (Table 3). After categorizing the QTc interval according to tertiles value(T1: $\leq 421 \mathrm{~ms} ; \mathrm{T} 2: 422-444 \mathrm{~ms}$; and T3: $\geq$ 445ms), defined patients in QTc T1 group as reference, logistic regression analyses were performed to evaluate the relationship between QTc interval and severe PAD(Table 4). In model 1, the ORs for severe PAD of patients in T2 and T3 groups were 1.95 (95\% confidence interval [Cl]: $1.08-3.52, P=0.027$ ) and 2.31 (95\% Cl: 1.27-4.20, $P=0.006$ ). In model 2 the ORs for severe PAD were 2.02 (95\% Cl: 1.08-3.76, $P=$ 0.027 ) and 2.00 (95\% Cl: 1.04-3.72, $P=0.038)$ for patients in T2 and T3 groups, after adjusting for clinical risk factors including age, sex, smoking, drinking, and diabetes duration. In model 3 the ORs for severe PAD were 2.07 (95\% Cl: 1.04-4.12, $P=0.037)$ and 2.05 (95\% Cl: 1.01-4.17, $P=0.046)$ for patients in T2 and T3 groups, after adjusted for risk factors in model 2 and clinical values including MAP, ALB, eGFR, Hb, LDL, HDL, HbA1c. 
Table 3

Univariate logistic regression analyses of risk factors for DFUs patients with severe PAD

\begin{tabular}{|c|c|c|}
\hline Characteristic & $\mathrm{OR}(95 \mathrm{Cl} \%)$ & P-value \\
\hline Male (\%) & $1.437(0.882-2.340)$ & 0.146 \\
\hline Age (years) & $1.059(1.034-1.084)$ & $<0.001$ \\
\hline Smoking (\%) & $0.824(0.498-1.363)$ & 0.451 \\
\hline Alcohol use (\%) & $0.765(0.451-1.297)$ & 0.320 \\
\hline Diabetes duration (years) & $1.010(0.978-1.043)$ & 0.544 \\
\hline Diabetic foot duration (day) & $1.002(1.000-1.003)$ & 0.060 \\
\hline Hypertension (\%) & $3.297(1.934-5.621)$ & $<0.001$ \\
\hline $\mathrm{SBP}(\mathrm{mmHg})$ & $1.009(0.998-1.020)$ & 0.106 \\
\hline $\mathrm{DBP}(\mathrm{mmHg})$ & $1.003(0.983-1.025)$ & 0.745 \\
\hline MAP $(\mathrm{mmHg})$ & $1.011(0.992-1.029)$ & 0.267 \\
\hline Creatinine $(\mu \mathrm{mol} / \mathrm{l})$ & $1.004(1.001-1.008)$ & 0.022 \\
\hline eGFR (EPI) (mL/min/1.73m2) & $0.985(0.976-0.993)$ & 0.001 \\
\hline HbA1c (\%) & $0.964(0.893-1.040)$ & 0.342 \\
\hline ALB (g/L) & $1.009(0.967-1.052)$ & 0.692 \\
\hline $\mathrm{Hb}(\mathrm{g} / \mathrm{L})$ & $0.996(0.983-1.008)$ & 0.478 \\
\hline TC (mmol/L) & $1.038(0.863-1.248)$ & 0.692 \\
\hline $\mathrm{TG}(\mathrm{mmol} / \mathrm{L})$ & $1.064(0.853-1.325)$ & 0.583 \\
\hline $\mathrm{HDL}-\mathrm{C}(\mathrm{mmol} / \mathrm{L})$ & $0.702(0.352-1.398)$ & 0.314 \\
\hline LDL-C (mmol/L) & $1.001(0.777-1.289)$ & 0.994 \\
\hline QTc (ms) & $1.010(1.002-1.018)$ & 0.014 \\
\hline
\end{tabular}


Table 4

Tertiles QTc and risk of DFUs patients with severe PAD

\begin{tabular}{|c|c|c|c|}
\hline & QTc & OR (95\%Cl) & P-value \\
\hline \multirow[t]{3}{*}{ Model 1} & $\mathrm{~T} 1$ ( $\leq 421 \mathrm{~ms})$ & 1 & 0.015 \\
\hline & T2 (422-444ms) & $1.95(1.08-3.52)$ & 0.027 \\
\hline & T3 ( $\geq 445 \mathrm{~ms})$ & $2.31(1.27-4.20)$ & 0.006 \\
\hline \multirow[t]{3}{*}{ Model 2} & $\mathrm{~T} 1(\leq 421 \mathrm{~ms})$ & 1 & 0.048 \\
\hline & T2 (422-444ms) & $2.02(1.08-3.76)$ & 0.027 \\
\hline & T3 ( $\geq 445 \mathrm{~ms})$ & $2.00(1.04-3.72)$ & 0.038 \\
\hline \multirow[t]{3}{*}{ Model 3} & $\mathrm{~T} 1(\leq 421 \mathrm{~ms})$ & 1 & 0.063 \\
\hline & T2 (422-444ms) & $2.07(1.04-4.12)$ & 0.037 \\
\hline & T3 ( $\geq 445 \mathrm{~ms})$ & $2.05(1.01-4.17)$ & 0.046 \\
\hline \multicolumn{4}{|c|}{ Model 1. Calculate by univariate logistic regression. } \\
\hline \multicolumn{4}{|c|}{ Model 2. Adjusted for risk factors including age, sex, smoking, drinking, diabetes duration. } \\
\hline \multicolumn{4}{|c|}{$\begin{array}{l}\text { Model 3. Adjusted for risk factors in model } 2 \text { and clinical values including MAP, ALB, eGFR, Hb, LDL, } \\
\mathrm{HDL}, \mathrm{HbA} 1 \mathrm{c} \text {. }\end{array}$} \\
\hline
\end{tabular}

\section{Discussion}

Identifying PAD in DFUs patients is important, given its association with failure to heal, amputation, CVDs and increased risk of mortality. Earlier assessment of the severity of PAD is required to determine the need for revascularization to promote ulcer healing ${ }^{[4]}$. However, most of the PAD in patients with diabetes is asymptomatic. Therefore, a profound understanding of potential risk factors in the severity of PAD in DFUs patients is imperiously needed, which might be helpful for early identification and subsequent initiation of therapy for subjects with severe PAD in DFUs patients.

The present study revealed a positive association between QTc interval and severe PAD in DFUs patients. Longer QTC and higher prevalence of prolonged QTC were found in DFUs patients with severe PAD. Longer QTc was significantly and independently associated with increased risks of severe PAD.

The Insulin Resistance Atherosclerosis Study including 1,577 subjects found that QT interval was prolonged in type 2 diabetes, even in newly diagnosed diabetes ${ }^{[9]}$. A Japan study ${ }^{[26]}$ found that neuropathy, nephropathy and the multiplicity of the microvascular complications were independently associated with QTC in patients with type 2 diabetes. Studies ${ }^{[19,21]}$ found associations between subclinical atherosclerosis marker: carotid intima media thickness and QTC prolongation in a clinically 
healthy population and in patients with type 2 diabetes. Pulse wave velocity is another established subclinical atherosclerosis marker. A link between pulse wave velocity and QTc have been found in clinically healthy population of Japanese ${ }^{[20]}$. Prolonged QTC was found to be associated with an increased risk of newly developed and a higher incidence of PAD, which was diagnosed as anklebrachial index $(\mathrm{ABI})<0.9$ or $>1.4$ at either side in a general population of china ${ }^{[18]}$. Few studies have addressed the association of QTc with DFUs. Katarina Fagher et al found in DFUs patients, QTC prolongation was associated with increased mortality ${ }^{[17,27]}$ and hyperbaric oxygen therapy might protect against QTc prolongation [28]. Shumin Wang found QTc prolongation was associated with a higher CVDs mortality in DFU patients, but it cannot predict ulcer healing or recurrence. The present study extends the associations to the severity of PAD in DFUs patients.

In accordance with previous study ${ }^{[29]}$ which found DFUs patients with prolonged QTc tended to have higher prevalence of severe DFUs (Wagner 3 to 5 degrees) in China, the present study found that the prevalence of severe DFUs (Wagner grade score $\geq 3$ ) was positively correlated with QTc. The severity of DFUs maybe can be partly explained by the co-existing severe PAD. However, in this study, DFUs patients with severe PAD had higher prevalence of severe DFUs, but did not reach statistical significance.

PAD has been classified as an equal risk factor for CVDs. Patients with PAD have an equivalent cardiovascular risk to patients with previous myocardial infarction ${ }^{[30]}$. Studies indicated that QTc was associated with the risk of CVDs in different populations ${ }^{[12,13,16,31]}$. Patients with severe PAD have a high risk of CVDs, which might affect QTC.

Studies have indicated that QTc is associated with age ${ }^{[32]}$, glycemic control ${ }^{[33]}$, hypertension ${ }^{[9]}$, hyperuricemia ${ }^{[34]}$, hyperinsulinemia ${ }^{[35]}$ and metabolic syndrome ${ }^{[36]}$, which are risk factors for the occurrence of PAD events in patients with diabetes.

The mechanism underlying the association between QTC and severe PAD has not been fully elucidated. PAD is usually caused by atherosclerosis. Other causes may be inflammation ${ }^{[37]}$, which can reduce vascular nitric oxide bioavailability ${ }^{[38]}$. Then inhibit the $\mathrm{Ca}^{2+}$-ATPase and $\mathrm{K}^{+} / \mathrm{Na}^{+}$-ATPase, leading to an increase of cytosolic free calcium and a prolongation of myocardial repolarization ${ }^{[39]}$.

The strengths of this study included a more precise measurement: duplex ultrasonography. Duplex ultrasonography is mostly used in detecting and localizing lesions in different territories of the vascular, and quantifying their grade of severity with the application of velocity and pressure gradient criteria. It can diagnose arterial disease at a very early stage ${ }^{[40]}$. Duplex ultrasonography is often recommended as the first-line non-invasive investigation for people with PAD. It has $85-90 \%$ sensitivity and $>95 \%$ specificity to detect stenosis $>50 \%{ }^{[41]}$. To our knowledge, this is the first study to address the associations between QTC and severe PAD in DFUs patients based on the measurements of duplex ultrasonography. Second, the participants of the present study were from multi-center including six different medical institutions. Therefore, the results may be applicable to general DFUs populations. The 
present study also has some limitations. Firstly, the sample size is relatively small, the result needs to be verified in a more larger sample. Second, because of the basic features of the cross-sectional study, we could not determine a cause-effect relationship between QTc and severe PAD in DFUs patients. Larger prospective cohort studies are needed for further exploration.

\section{Conclusion}

The present study demonstrated an independently positive association of QTc with severity of PAD in patients with DFUs. In patients with DFUs, prolonged QTc may indicate not only cardiac pathology, but also the worse progression of peripheral atherosclerosis in early stage.

\section{Abbreviations}

DFUs, diabetes and foot ulcers; PAD, peripheral arterial disease ; QTc, Heart-rate-corrected QT; CVDs, cardiovascular diseases; IWGDF, International Working Group on the Diabetic Foot; SBP, systolic blood pressure; DBP, diastolic blood pressure; MAP: mean arterial pressure; HDL, high-density lipoprotein; LDL, low density lipoprotein; TC, total cholesterol; TG, triglyceride; HbA1c, hemoglobin A1c; ALB: albumin; Hb, hemoglobin; eGFR, estimated glomerular filtration rate; IQR, interquartile range; OR, odd ratio; $\mathrm{Cl}$, confidence interval.

\section{Declarations}

\section{Ethics approval and consent to participate:}

The study protocol was approved by the ethics committee of the First Affiliated Hospital of Wenzhou Medical University. Written informed consent was obtained from all patients prior to their participation.

\section{Consent for publication:}

Not applicable.

\section{Availability of data and materials:}

The datasets used and analysed during the current study are available from the corresponding author on reasonable request.

\section{Competing interests:}

All authors: no conflicts of interest to disclose. 


\section{Funding/support:}

This work was supported by grants from the Wenzhou Science \& Technology Burea

(Y20180609).

\section{Author's contributions:}

J H: Software, Investigation, Writing-original draft

W-Y L: Software, Investigation

X H: Writing - review \& editing

F-F J: Data curation

Z-R X: Data curation

F L: Data curation

F-X S: Supervision

H Z: Conceptualization, Writing - review \& editing

All authors read and approved the final manuscript.

\section{Acknowledgements:}

We would like to acknowledge the helpful comments on this paper received from our reviewers and all the patients who participated in the study.

\section{References}

1. Singh N, Armstrong DG, Lipsky BA. Preventing foot ulcers in patients with diabetes. Jama. 2005;293(2):217 - 28. https://doi.org/10.1001/jama.293.2.217.

2. Boulton AJ, Vileikyte L, Ragnarson-Tennvall G, Apelqvist J. The global burden of diabetic foot disease. Lancet. 2005;366(9498):1719-24. https://doi.org/10.1016/s0140-6736(05)67698-2.

3. Prompers L, Huijberts M, Apelqvist J, Jude E, Piaggesi A, Bakker K, et al. High prevalence of ischaemia, infection and serious comorbidity in patients with diabetic foot disease in Europe. Baseline results from the Eurodiale study. Diabetologia. 2007;50(1):18-25. https://doi.org/10.1007/s00125-006-0491-1. 
4. Brownrigg JR, Schaper NC, Hinchliffe RJ. Diagnosis and assessment of peripheral arterial disease in the diabetic foot. Diabetic medicine: a journal of the British Diabetic Association. 2015;32(6):738 47. https://doi.org/10.1111/dme.12749.

5. Peter-Riesch B. The Diabetic Foot: The Never-Ending Challenge. Endocr Dev. 2016;31:108-34. https://doi.org/10.1159/000439409.

6. Rautaharju PM, Surawicz B, Gettes LS, Bailey JJ, Childers R, Deal BJ, et al. AHA/ACCF/HRS recommendations for the standardization and interpretation of the electrocardiogram: part IV: the ST segment, $T$ and $U$ waves, and the QT interval: a scientific statement from the American Heart Association Electrocardiography and Arrhythmias Committee, Council on Clinical Cardiology; the American College of Cardiology Foundation; and the Heart Rhythm Society. Endorsed by the International Society for Computerized Electrocardiology. J Am Coll Cardiol. 2009;53(11):982 - 91. https://doi.org/10.1016/j.jacc.2008.12.014.

7. Pappachan JM, Sebastian J, Bino BC, Jayaprakash K, Vijayakumar K, Sujathan P, et al. Cardiac autonomic neuropathy in diabetes mellitus: prevalence, risk factors and utility of corrected QT interval in the ECG for its diagnosis. Postgraduate medical journal. 2008;84(990):205 - 10. https://doi.org/10.1136/pgmj.2007.064048.

8. Veglio M, Chinaglia A, Cavallo-Perin P. QT interval, cardiovascular risk factors and risk of death in diabetes. J Endocrinol Investig. 2004;27(2):175 - 81. https://doi.org/10.1007/bf03346265.

9. Festa A, D'Agostino R Jr, Rautaharju P, Mykkänen L, Haffner SM. Relation of systemic blood pressure, left ventricular mass, insulin sensitivity, and coronary artery disease to QT interval duration in nondiabetic and type 2 diabetic subjects. The American journal of cardiology. 2000;86(10):111722. https://doi.org/10.1016/s0002-9149(00)01170-x.

10. Murphy NP, Ford-Adams ME, Ong KK, Harris ND, Keane SM, Davies C, et al. Prolonged cardiac repolarisation during spontaneous nocturnal hypoglycaemia in children and adolescents with type 1 diabetes. Diabetologia. 2004;47(11):1940-7. https://doi.org/10.1007/s00125-004-1552-y.

11. Mylona M, Liatis S, Anastasiadis G, Kapelios C, Kokkinos A. Severe iatrogenic hypoglycaemia requiring medical assistance is associated with concurrent prolongation of the QTc interval. Diabetes Res Clin Pract. 2020;161:108038. https://doi.org/10.1016/j.diabres.2020.108038.

12. Cox AJ, Azeem A, Yeboah J, Soliman EZ, Aggarwal SR, Bertoni AG, et al. Heart rate-corrected QT interval is an independent predictor of all-cause and cardiovascular mortality in individuals with type 2 diabetes: the Diabetes Heart Study. Diabetes Care. 2014;37(5):145461. https://doi.org/10.2337/dc13-1257.

13. Beinart R, Zhang Y, Lima JA, Bluemke DA, Soliman EZ, Heckbert SR, et al. The QT interval is associated with incident cardiovascular events: the MESA study. J Am Coll Cardiol. 2014;64(20):2111-9. https://doi.org/10.1016/j.jacc.2014.08.039.

14. Reinier K, Nichols GA, Huertas-Vazquez A, Uy-Evanado A, Teodorescu C, Stecker EC, et al. Distinctive Clinical Profile of Blacks Versus Whites Presenting With Sudden Cardiac Arrest. Circulation. 2015;132(5):380-7. https://doi.org/10.1161/circulationaha.115.015673. 
15. Ishikawa J, Ishikawa S, Kario K. Prolonged corrected QT interval is predictive of future stroke events even in subjects without ECG-diagnosed left ventricular hypertrophy. Hypertension (Dallas, Tex: 1979). 2015;65(3):554 - 60. https://doi.org/10.1161/hypertensionaha.114.04722.

16. Wu J, Nizhamuding D, Liu P, Jiang Y, Qiang H, Sun C, et al. QT interval prolongation in patients with acute ischemic stroke: a report in northwest China. J Int Med Res. 2019;47(12):598695. https://doi.org/10.1177/0300060519879852.

17. Fagher K, Löndahl M. The impact of metabolic control and QTc prolongation on all-cause mortality in patients with type 2 diabetes and foot ulcers. Diabetologia. 2013;56(5):1140-7. .https://doi.org/10.1007/s00125-013-2860-x.

18. Deng C, Niu J, Xuan L, Zhu W, Dai H, Zhao Z, et al. Association of QTc Interval with Risk of Cardiovascular Diseases and Related Vascular Traits: A Prospective and Longitudinal Analysis. Global heart. 2020;15(1):13. https://doi.org/10.5334/gh.533.

19. Strohmer B, Pichler M, Iglseder B, Paulweber B. Relationship of QT interval duration with carotid intima media thickness in a clinically healthy population undergoing cardiovascular risk screening. Journal of internal medicine. 2005;257(3):238 - 46. https://doi.org/10.1111/j.13652796.2004.01436.x.

20. Maebuchi D, Arima H, Ninomiya T, Yonemoto K, Kubo M, Doi Y, et al. Arterial stiffness and QT interval prolongation in a general population: the Hisayama study. Hypertension research: official journal of the Japanese Society of Hypertension. 2008;31(7):1339-45. .https://doi.org/10.1291/hypres.31.1339.

21. Takebayashi K, Aso Y, Matsutomo R, Wakabayashi S, Inukai T. Association between the corrected QT intervals and combined intimal-medial thickness of the carotid artery in patients with type 2 diabetes. Metab Clin Exp. 2004;53(9):1152-7. .https://doi.org/10.1016/j.metabol.2004.03.018.

22. Lipsky BA, Aragón-Sánchez J, Diggle M, Embil J, Kono S, Lavery L, et al. IWGDF guidance on the diagnosis and management of foot infections in persons with diabetes. Diab/Metab Res Rev. 2016;32(Suppl 1):45-74. https://doi.org/10.1002/dmrr.2699.

23. Roden DM. Drug-induced prolongation of the QT interval. N Engl J Med. 2004;350(10):1013-22. https://doi.org/10.1056/NEJMra032426.

24. Bravo-Molina A, Linares-Palomino JP, Vera-Arroyo B, Salmerón-Febres LM, Ros-Díe E. Inter-observer agreement of the Wagner, University of Texas and PEDIS classification systems for the diabetic foot syndrome. Foot ankle surgery: official journal of the European Society of Foot Ankle Surgeons. 2018;24(1):60-4 https://doi.org/10.1016/j.fas.2016.10.009.

25. Levey AS, Stevens LA, Schmid CH, Zhang YL, Castro AF 3rd, Feldman HI, et al. A new equation to estimate glomerular filtration rate. Ann Intern Med. 2009;150(9):604 - 12. https://doi.org/10.7326/0003-4819-150-9-200905050-00006.

26. Kobayashi S, Nagao M, Asai A, Fukuda I, Oikawa S, Sugihara H. Severity and multiplicity of microvascular complications are associated with QT interval prolongation in patients with type 2 diabetes. Journal of diabetes investigation. 2018;9(4):946 - 51. https://doi.org/10.1111/jdi.12772. 
27. Fagher K, Nilsson A, Löndahl M. Heart rate-corrected QT interval prolongation as a prognostic marker for 3-year survival in people with Type 2 diabetes undergoing above-ankle amputation. Diabetic medicine: a journal of the British Diabetic Association. 2015;32(5):679 - 85. https://doi.org/10.1111/dme.12632.

28. Fagher K, Katzman P, Löndahl M. Hyperbaric oxygen therapy reduces the risk of QTc interval prolongation in patients with diabetes and hard-to-heal foot ulcers. J Diabetes Complicat. 2015;29(8):1198-202. https://doi.org/10.1016/j.jdiacomp.2015.07.023.

29. Wang S, He Y, Xu L, Zhang S, Gu X, Gu J, et al. Association between QTc interval prolongation and outcomes of diabetic foot ulcers: Data from a 4-year follow-up study in China. Diabetes Res Clin Pract. 2018;138:26-34. https://doi.org/10.1016/j.diabres.2018.01.021.

30. Zemaitis MR, Boll JM, Dreyer MA. Peripheral Arterial Disease. StatPearls. Treasure Island (FL): StatPearls Publishing Copyright @ 2020, StatPearls Publishing LLC.; 2020.

31. Ko GT, Chan JC, Critchley JA, Cockram CS. Cardiovascular disease in chinese type 2 diabetic women is associated with a prolonged QTc interval. Int J Cardiol. 2000;76(1):7580. https://doi.org/10.1016/s0167-5273(00)00372-7.

32. Vandael E, Vandenberk B, Vandenberghe J, Willems R, Foulon V. Risk factors for QTc-prolongation: systematic review of the evidence. International journal of clinical pharmacy. 2017;39(1):16-25. https://doi.org/10.1007/s11096-016-0414-2.

33. Su JB, Yang XH, Zhang XL, Cai HL, Huang HY, Zhao LH, et al. The association of long-term glycaemic variability versus sustained chronic hyperglycaemia with heart rate-corrected QT interval in patients with type 2 diabetes. PloS one. 2017;12(8):e0183055. https://doi.org/10.1371/journal.pone.0183055.

34. Guo X, Li Z, Liu Y, Yu S, Yang H, Zheng L, et al. Sex-specific association between serum uric acid and prolonged corrected QT interval: Result from a general rural Chinese population. Medicine. 2016;95(50):e5568. https://doi.org/10.1097/md.0000000000005568.

35. van Noord C, Sturkenboom MC, Straus SM, Hofman A, Kors JA, Witteman JC, et al. Serum glucose and insulin are associated with QTc and RR intervals in nondiabetic elderly. European journal of endocrinology. 2010;162(2):241-8. https://doi.org/10.1530/eje-09-0878.

36. Guo X, Li Z, Guo L, Yu S, Yang H, Zheng L, et al. Effects of Metabolically Healthy and Unhealthy Obesity on Prolongation of Corrected QT Interval. The American journal of cardiology. 2017;119(8):1199-204. https://doi.org/10.1016/j.amjcard.2016.12.033.

37. Simon F, Oberhuber A, Floros N, Düppers P, Schelzig H, Duran M. Pathophysiology of chronic limb ischemia. Gefasschirurgie: Zeitschrift fur vaskulare und endovaskulare Chirurgie : Organ der Deutschen und der Osterreichischen Gesellschaft fur Gefasschirurgie unter Mitarbeit der Schweizerischen Gesellschaft fur Gefasschirurgie. 2018;23(Suppl 1):13 8.https://doi.org/10.1007/s00772-018-0380-1.

38. Shi Y, Vanhoutte PM. Macro- and microvascular endothelial dysfunction in diabetes. Journal of diabetes. 2017;9(5):434-49. https://doi.org/10.1111/1753-0407.12521. 
39. Fiorentini A, Perciaccante A, Valente R, Paris A, Serra P, Tubani L. The correlation among QTc interval, hyperglycaemia and the impaired autonomic activity. Autonomic neuroscience: basic clinical. 2010;154(1-2):94-8. https://doi.org/10.1016/j.autneu.2009.11.006.

40. Vlachopoulos C, Georgakopoulos C, Koutagiar I, Tousoulis D. Diagnostic modalities in peripheral artery disease. Curr Opin Pharmacol. 2018;39:68-76. https://doi.org/10.1016/j.coph.2018.02.010.

41. Collins R, Cranny G, Burch J, Aguiar-lbáñez R, Craig D, Wright K, et al. A systematic review of duplex ultrasound, magnetic resonance angiography and computed tomography angiography for the diagnosis and assessment of symptomatic, lower limb peripheral arterial disease. Health technology assessment (Winchester, England). 2007;11(20):iii-iv, xi-xiii, 1-184.https://doi.org/10.3310/hta11200.

\section{Figures}

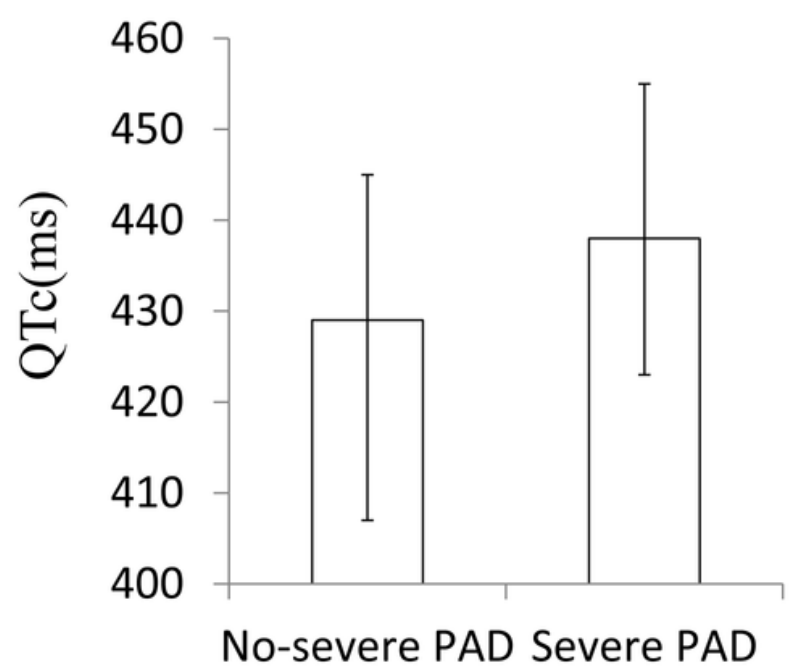

(a)

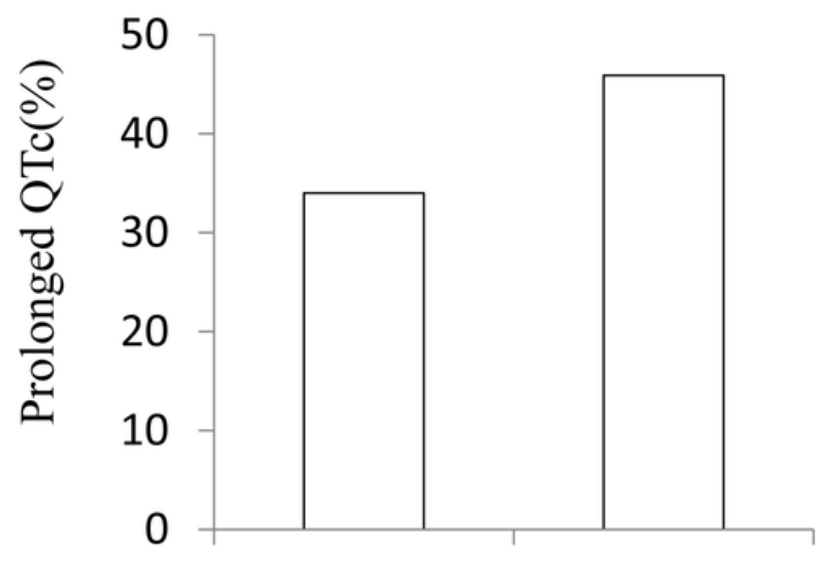

No-severe PAD Severe PAD

(b)

Figure 1 
QTc interval (ms) (a) ( $P=0.004)$ and Prolonged QTc $(\%)(b)(P=0.042)$ comparing No-severe PAD group with severe PAD group 